\title{
Anastrozole plus leuprorelin in early maturing girls with compromised growth: the "GAIL" study
}

\author{
D. T. Papadimitriou ${ }^{1,2} \cdot$ E. Dermitzaki ${ }^{2} \cdot$ M. Papagianni $^{3} \cdot$ G. Papaioannou $^{4}$ • \\ V. Papaevangelou ${ }^{2} \cdot$ A. Papadimitriou ${ }^{2}$
}

Received: 30 August 2015 / Accepted: 7 October 2015 / Published online: 27 October 2015

(C) The Author(s) 2015. This article is published with open access at Springerlink.com

\begin{abstract}
Purpose Aromatase inhibitors have been used to increase predicted adult height (PAH) in boys but in girls only in McCune-Albright syndrome. We investigated whether anastrozole combined with leuprorelin for up to 2 years is safe and effective in improving PAH in girls with early puberty and compromised growth, compared to leuprorelin alone.

Methods The "GAIL" study: girls treated with an aromatase inhibitor and an LHRH analogue, ISRCTN11469487, was a 7-year prospective phase IIa study with parallel design, performed at Athens Medical Center (C-A), and Attikon University Hospital, Athens, Greece (C-B). Forty girls, consecutively referred for early puberty (onset 7.5-9 years) with a $\mathrm{PAH}<-2$ or $>1.5 \mathrm{SD}$ lower than their target height (TH), were included. Twenty started on leuprorelin sc/im $0.3 \mathrm{mg} / \mathrm{kg} / \mathrm{month}$ plus anastrozole $1 \mathrm{mg} / \mathrm{d}$ p.o. (group-A, C-A) and 20 on leuprorelin (group-B, C-B) for 2 years or until the age of 10 years. Groups did not differ in age, height, BMI, bone age advancement (BAA), and distance of PAH from TH. Follow-up was at $6,12,18$, and $24 \mathrm{~m}$.
\end{abstract}

D. T. Papadimitriou

info@pedoendo.gr

1 Department of Pediatric-Endocrinology and Diabetes, Athens Medical Center, 58, av. Kifissias, Maroussi, 15125 Athens, Greece

2 Third Department of Pediatrics, "Attikon" University Hospital, Haidari, 12462 Athens, Greece

3 Third Department of Pediatrics, Hippokrateion General Hospital of Thessaloniki, Aristotle University of Thessaloniki, 54642 Thessaloniki, Greece

4 Department of Radiology, Mitera Maternity and Children's Hospital, Maroussi, 15123 Athens, Greece
Results Reduction in BAA was significantly higher in group-A compared to group-B already by $6 \mathrm{~m}$. Despite the transiently significant decrease in height velocity in groupA, gain in PAH SD was almost double by 12 and $18 \mathrm{~m}$ vs group-B and reached the maximum of $+1.21 \pm 0.45$ $(7.51 \mathrm{~cm})$ vs $+0.31 \pm 0.37(1.92 \mathrm{~cm}, p=0.001)$ in group$\mathrm{B}$ at $24 \mathrm{~m}$. Group-A had no clinical or biochemical hyperandrogenism, unchanged normal bone density, and lumbar spine X-rays.

Conclusion The co-administration of anastrozole with leuprorelin safely improves PAH in girls with compromised growth.

Keywords Aromatase inhibitors $\cdot$ Anastrozole $\cdot$ LHRH analogues $\cdot$ Early puberty $\cdot$ Girls

\section{Introduction}

Third generation aromatase inhibitors (AI), mainly anastrozole and letrozole, have been used to increase predicted adult height $(\mathrm{PAH})[1,2]$ in boys with constitutional delay of growth and puberty (CDGP) [3], idiopathic short stature (ISS) [4-6], and growth hormone deficiency (GHD) [6,7], as well as in testotoxicosis [8], and gynecomastia [9-11], but in girls only in the context of McCune-Albright syndrome [12-14] apart from one case report of a girl with a recurrent autonomous ovarian cyst [15]. The reluctance of using of aromatase inhibitors in girls stems from the theoretical concern of secondary hyperandrogenism and ovarian cyst formation $[16,17]$.

To relieve and overcome these concerns, we combined anastrozole with an LHRH analogue in girls with precocious puberty (PP) or early puberty (EP) and compromised 
growth potential [median PAH $145.4 \mathrm{~cm}$ with a median target height $(\mathrm{TH})$ of $161 \mathrm{~cm}$ ] in a small pilot clinical trial [18]. In that study, 5 girls (aged 6.3-11.5 years) received leuprorelin $11.25 \mathrm{mg} / 12$ weeks s.c./i.m. and anastrozole $1 \mathrm{mg} /$ day p.o. for $1-3$ years. There was a net significant increase in PAH of $+4.5 \mathrm{~cm}$ already by the end of the $1 \mathrm{st}$ year. None developed ovarian cysts or other signs of hyperandrogenism or any other systematic side effects, while bone mineral density (BMD) evaluated yearly remained unchanged [DXA scans showed $z$ scores (corrected for height) within normal range for BA without significant inter-patient changes].

It has been already shown that in EP and in borderline $\mathrm{PP}$, inhibition of puberty alone is not as effective as initially expected in improving $\mathrm{PAH}$, with most studies showing a gain of $2 \mathrm{~cm}$ or less after a 2-year treatment with an LHRH analogue (LHRHa) [19]. On the other hand, atypical forms of early puberty not driven by LH, such as those occurring in cases of premature or exaggerated adrenarche, do not seem to respond to LHRH analogues at least in terms of bone maturation and gain in adult height [20].

These facts led us to plan and implement a phase IIa prospective parallel group study, the "GAIL" study: girls treated with an Aromatase Inhibitor and Leuprorelin, to investigate whether the combination of anastrozole and leuprorelin could significantly improve PAH in girls with EP and a compromised growth potential, compared to inhibition of puberty alone.

\section{Materials and methods}

The "GAIL" study ISRCTN11469487 was a 7-year prospective study that was performed between 2008 and 2014 in the pediatric endocrine units of the Athens Medical Center (Center-A) and of the Attikon University Hospital (Center-B), Athens, Greece. Inclusion started on March 2008 and ended on December 2013. The institutional review boards of both institutions approved the study. Written informed consent was obtained from at least one parent in group-B and from both parents in group- $\mathrm{A}$, as this was an off-label treatment.

\section{Inclusion criteria}

Forty girls with idiopathic early puberty, i.e. breast development between 7.5 and 9 years [21], with a PAH—calculated according to the Bayley-Pinneau method using the average girls' prediction tables [22, 23]-lower than -2 or -1.5 SD lower than their TH (mid parental height $-6.5 \mathrm{~cm}$ ), previously naïve to any hormonal therapy, consecutively referred to the above centers, were enrolled for a maximum period of 2 years, or until the age of 10 years [24]. Girls with organic PP, syndromic, systemic or hereditary conditions that either impair growth or associate with PP, as well as bone diseases related to short stature (i.e. hypochondroplasia), were excluded from the study. Diagnosis of PP was based upon clinical examination and laboratory evaluation including a positive LHRH test [peak $\mathrm{LH} \geq 5 \mathrm{IU} / \mathrm{L}$ at $30^{\prime}$ or $60^{\prime}$ after i.v. administration of gonadorelin $100 \mu \mathrm{g} / \mathrm{m}^{2}-\max$ $100 \mu \mathrm{g}\left(\right.$ Relefact LHRH $^{\circledR}$, Ferring SAS)] associated with elevated basal $E_{2} \geq 15 \mathrm{pg} / \mathrm{mL}$ and pubertal configuration of the internal genitalia on the pelvic ultrasound: maximum uterine length $\geq 35 \mathrm{~mm}$, pear shaped (uterine/cervix width $>1$ ), ovaries $\geq 3 \mathrm{~mL}$ with the presence of stimulated follicles $\geq 6 \mathrm{~mm}$ in diameter). BA was advanced more than the expected difference in years between their height percentile and their TH percentile, as these girls did not follow the well-recognized pattern of constitutional advancement of growth and puberty (CAG) [25]. Girls in Center-B were offered inhibition of puberty with leuprorelin and those in Center-A inhibition of puberty with leuprorelin combined to the AI anastrozole. Patient characteristics forming group-A and group-B are shown in detail in Table 1.

\section{Study design}

A complete physical examination with accurate height measurements (and of both parents), pubertal Tanner staging, a bone age X-ray, a pelvic ultrasound by a pediatric radiologist, as well as the required biochemical testing (at $0800 \mathrm{~h}$ and after an overnight fast) were obtained at inclusion. These studies were repeated on the day of the scheduled injection with leuprorelin every 6 months during follow-up.

Each girl enrolled was consecutively followed by the same experienced Pediatric Endocrinologist: D.T.P in

Table 1 Patient characteristics (mean \pm SD)

\begin{tabular}{lllllll}
\hline Group & Age (years) & Height (SDS) & BMI (SDS) & TH (SDS) & TH-PAH (SDS) & $\begin{array}{l}\text { Bone age advancement } \\
\text { (years) }\end{array}$ \\
\hline A: LHRHa + AI $(n=20)$ & $8.91( \pm 0.98)$ & $-0.19( \pm 1.36)$ & $1.15( \pm 0.89)$ & $-0.27( \pm 0.80)$ & $-2.17( \pm 1.00)$ & $1.88( \pm 1.11)$ \\
B: LHRHa $(n=20)$ & $8.46( \pm 0.65)$ & $0.53( \pm 0.83)$ & $1.13( \pm 1.08)$ & $0.15( \pm 0.73)$ & $-1.81( \pm 0.58)$ & $1.95( \pm 0.67)$ \\
$p$ & 0.058 & 0.06 & 0.47 & 0.055 & 0.09 & 0.40 \\
\hline
\end{tabular}

LHRHa LHRH analogue, $A I$ aromatase inhibitor, $B A$ bone age, $B M I$ body mass index, $T H$ target height, $P A H$ predicted adult height 
Fig. 1 A STARD (STAndards for the Reporting of Diagnostic accuracy studies) flow diagram showing the disposition of subjects participating in the current study

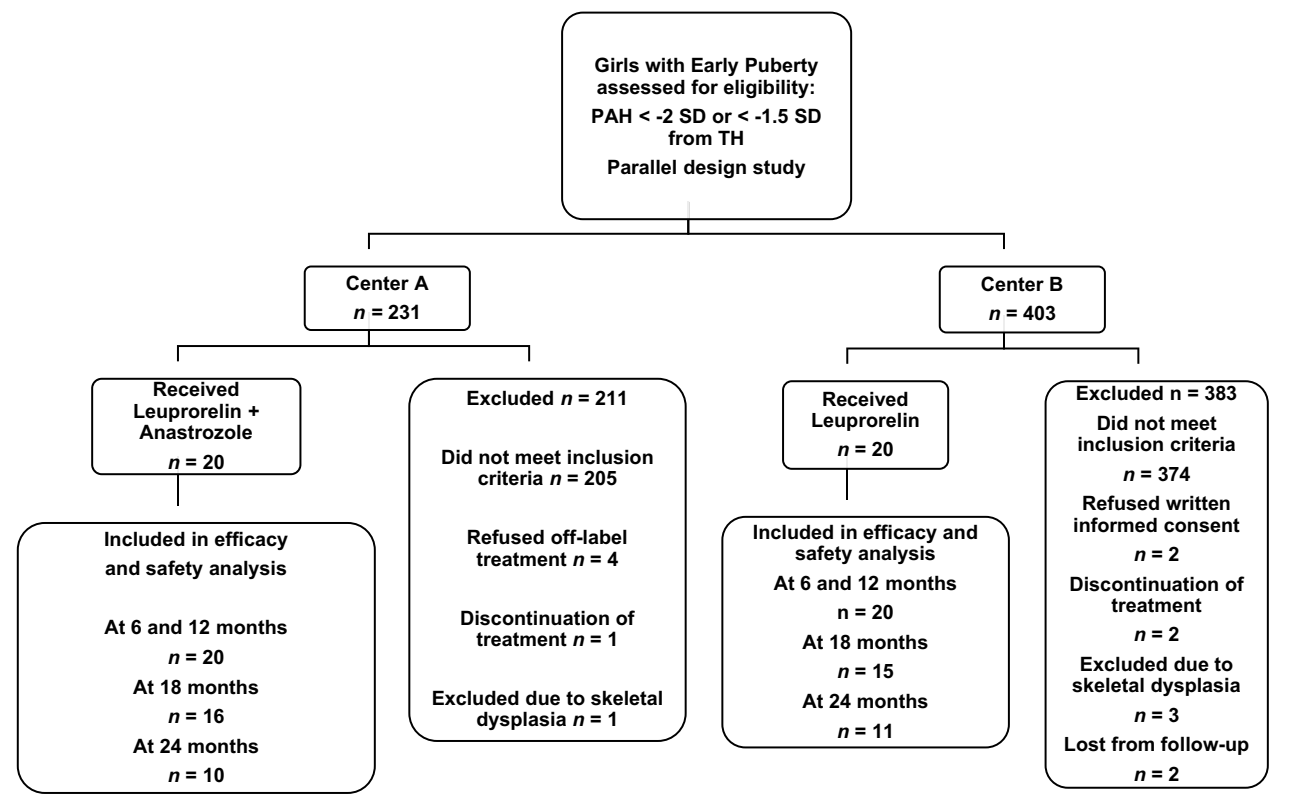

Center-A and A.P. in Center-B. Bone ages were evaluated blindly according to the Atlas of Greulich and Pyle by an experienced Pediatric Radiologist G.P., who did not work in either institution. G.P. did not have access to the previous readings or the growth chart in the patients' medical files, nor the regimen the patients were receiving apart from their birth dates.

All measurements, BA readings, and PAH calculations were entered, calculated by and analyzed in growth analyser 3.5 (Copyright $\odot$ 2001-2006, Dutch growth foundation), using the country default growth curves (for height: Papadimitriou A. 1995, for BMI: The Netherlands 1997, for height velocity: British 1996).

At inclusion a blood count, concentrations of lipids, glucose, calcium, phosphate, alkaline phosphatase, liver enzymes, total vitamin $\mathrm{D}^{*}$ and parathyroid hormone* as well as LH*, FSH*, testosterone, and estradiol (*ECLIA, Elecsys immunoassay analyzer, Roche) were performed. Sex steroids and 17OH-progesterone levels were measured by liquid chromatography/tandem mass spectrometry (LC/ MS-MS). $17 \mathrm{OH}$-progesterone was $<1.5 \mathrm{ng} / \mathrm{mL}$ in all cases excluding the possibility of late onset congenital adrenal hyperplasia (CAH). Those with a vitamin D deficiency (i.e. total vit $\mathrm{D}<20 \mathrm{ng} / \mathrm{mL}$ ) received proper replacement therapy (i.e. $2000 \mathrm{IU}$ cholecalciferol p.o. daily for 2 months and as needed thereafter) [26].

Dual-energy X-ray absorptiometry (DXA) as well as anterior-posterior/lateral X-ray of the lumbar spine was performed at inclusion and yearly thereafter in groupA patients only. BMD was measured at the lumbar spine (L1-L4) by DXA with a Hologic QDR-1000 upgraded unit
(Hologic Inc., Bedford, MA, USA) and was expressed as $z$ scores (calculated according to the BA and corrected for height). As reference data for BMD were used the ones provided by the manufacturer of the Hologic densitometer, for Caucasians. The lumbar spine X-rays were evaluated by a pediatric radiologist and were re-evaluated each time in comparison with the previous ones in each patient.

Treatment for EP was with leuprorelin acetate $0.3 \mathrm{mg} /$ $\mathrm{kg} / \mathrm{month}$ with the 3-month $11.25 \mathrm{mg}$ depot s.c./i.m. injection (Elityran $\left.{ }^{\circledR}\right)$ [27]. All patients had an LHRH stimulation test $\left(0^{\prime}-30^{\prime}-60^{\prime}\right)$ performed on the day of and prior to the second scheduled leuprorelin injection with measurement of $E_{2}$ levels and evaluation of the internal genitalia maturation in the pelvic ultrasound.

Treatment with anastrozole tablets started simultaneously at a dose of $1 \mathrm{mg}$ once daily p.o. (Arimidex ${ }^{\circledR}$ ). Patients were followed at 6-month intervals. Parents were advised to report any sign of hyperandrogenism (acne, hirsutism, hair loss) as well as incidents of peculiar behavior. Medication was electronically prescribed and covered by the patient's social security at $75 \%$, which assured compliance with the treatment.

\section{Statistics}

Changes in PAH and in the rest of the parameters presented in the results section between baseline and at $6,12,18$, and 24 months of treatment was compared using only data from the girls that completed each visit. Analysis between groups was performed with the use of the two-sample twosided $t$ test. Significance was set as a $p$ value $<0.05$. 


\section{Results}

The flow chart of the study subjects is shown in Fig. 1. Subjects in group-A ( $n=20$ from Center-A) and group-B ( $n=20$ from Center-B) did not differ in age, height, BMI, BAA, and distance of $\mathrm{PAH}$ from TH (Table 1). Evolution of those parameters including also height velocity (HV) is presented in Table 2. Gain in PAH and BAA is presented in Fig. 2. All girls had adequate pubertal inhibition: peak $\mathrm{LH}<2$ IU/L-during an LHRH stimulation test $\left(0^{\prime}-30^{\prime}-60^{\prime}\right)$ performed on the day of and prior to the second scheduled leuprorelin injection, $E_{2}$ levels $<15 \mathrm{pg} / \mathrm{mL}$ and regression of breast development as well as of the internal genitalia maturation in the pelvic ultrasound (maximum uterine length $<35 \mathrm{~mm}$ with the ovaries regressing to $<3 \mathrm{~mL}$ ). The girls on LHRHa only did not present a significant reduction in $\mathrm{BA}$ advancement $(\mathrm{BAA}):+1.82 \pm 0.45$ at 24 months from $+1.95 \pm 0.67$ years at inclusion $(p=0.07)$. Despite the initial significant drop in $\mathrm{HV}$ of group-A at 6 months, which however, did not persist thereafter, there was a significant gain in $\mathrm{PAH}$ in group-A at 12 months: $+3.72 \mathrm{~cm}$ and even more at 18 : $+5.77 \mathrm{~cm}$ and at 24 months: $+7.51 \mathrm{~cm}$ compared to group-B: $+1.98 \mathrm{~cm}$ at 12 months $(p=0.01),+3.16 \mathrm{~cm}$ at 18 months $(p=0.02)$ and $+1.92 \mathrm{~cm}$ at 24 months $(p=0.001)$ (Table 2). This was achieved because of the significantly higher reduction in BAA of the group-A related to that of the group-B, statistically significant already at 6 months $(p<0.001)$ with a maximum at 24 months (Table 2).

Girls in group-A did not develop clinical or biochemical hyperandrogenism or any other side effect. Testosterone levels rose slightly but not significantly and did not exceed $0.5 \mathrm{ng} / \mathrm{ml}$ during treatment in any of the girls in group-A: $0.23 \pm 0.14$ at inclusion, $0.22 \pm 0.16(p=0.92)$ at 6 months, $0.39 \pm 0.34(p=0.14)$ at 12 months, $0.32 \pm 0.21(p=0.1)$ at 18 months, and $0.38 \pm 0.35$ $(p=0.58)$ at 24 months. None presented ovarian cysts or ovarian stromal hyperplasia and there were no reports of peculiar behavior in any of them. Hematocrit, biochemical, and lipid profiles did not change during treatment. DXA scans showed normal BMD $z$ scores for BA: $-0.04 \pm 1.1$ at inclusion, $-0.17 \pm 1.07$ at 12 months $(p=0.39)$, and $+0.35 \pm 1.14$ at 24 months $(p=0.24)$ without significant inter-patient change during treatment. X-rays of the lumbar spine did not show any abnormalities before, during,or at the end of treatment. Basal gonadotropins and estradiol levels were appropriately suppressed $(\mathrm{LH}<0.2 \mathrm{IU} / \mathrm{L}, \mathrm{FSH}$ $<2 \mathrm{IU} / \mathrm{L}$ and $E_{2}<15 \mathrm{pg} / \mathrm{mL}$ ) and did not differ between groups at any time point.

\section{Discussion}

With this study we investigated prospectively whether the combination of an AI to an LHRHa could significantly improve PAH in girls with EP and compromised growth, compared to inhibition of puberty alone. Although we acknowledge as a major limitation that this was not a randomized double-blind placebo controlled trial, the study design simulated randomization as much as possible and moreover there was a control group. A parallel study design was chosen, matching each arm of the study with each of the two participating centers as it was judged extremely difficult to obtain parental consent for a potentially offlabel treatment with the parents being blind to it. In order to avoid possible biases, every girl who was consecutively referred for pubertal evaluation in each center was assessed for eligibility and only those that met the inclusion criteria and had parental written informed consent entered the study. To increase accuracy, all the parameters presented in the results section were compared between baseline and at $6,12,18$, and 24 months using only data from those girls that completed each visit and not with the whole of each group at inclusion. We acknowledge the progressive decrease in sample size throughout the study, but at least $50 \%$ of the girls completed 2 years of treatment. This was due to the fact that many reached the age of 10 , while at the moment of data analysis still some of the girls had ongoing visits. The results, however, were straightforward showing a net gain of $+7.51 \mathrm{~cm}$ in $\mathrm{PAH}$ at 24 months in the girls treated with the combination therapy vs $+1.92 \mathrm{~cm}$ with inhibition of puberty alone.

The gain in PAH in the anastrozole group confirmed our preliminary results from the pilot study [18] and was in accordance with the abstract of A.L. Turpin et al. who presented a retrospective study, in which 7 from 19 girls treated with letrozole were concomitantly treated with LHRH analogues [28]. It was also comparable to those of Mauras et al. [7], in adolescent males with GHD and daily co-treatment with anastrozole, that resulted in a net increase in PAH of $6.8 \mathrm{~cm}$ at 36 months vs $1 \mathrm{~cm}$ in the placebo group. Similar results published recently by Neely EK et al. showed a gain in PAH of $4.2 \pm 3.5 \mathrm{~cm}$ in peripubertal boys with daily administration of anastrozole vs $1.4 \pm 4.4 \mathrm{~cm}$ with letrozole after 1 year [5]. While AI have nowadays become an established-even if still an off-label treatment in boys-and this is proven by the fact that recent studies compare directly letrozole to anastrozole in short boys without even a control group [5], to our knowledge this is the first prospective study ever conducted in girls, outside the context of McCune Albright syndrome. 


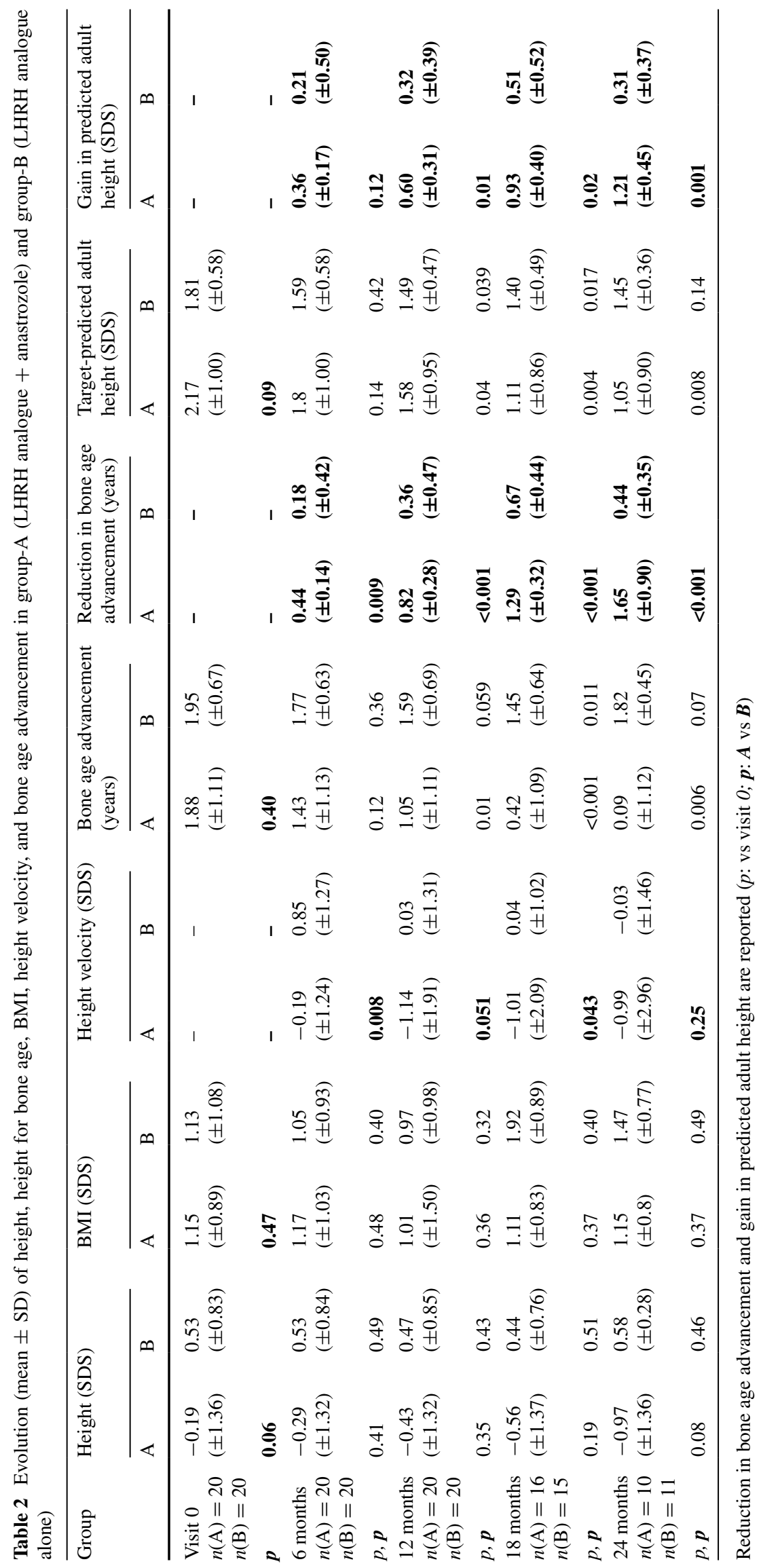


Fig. 2 Reduction in bone age advancement (BAA, years: left side) and gain in predicted adult height PAH (SDS: right side) in group-A (LHRHa $+\mathrm{AI})$ and group-B (LHRHa) at $6,12,18$, 24 months

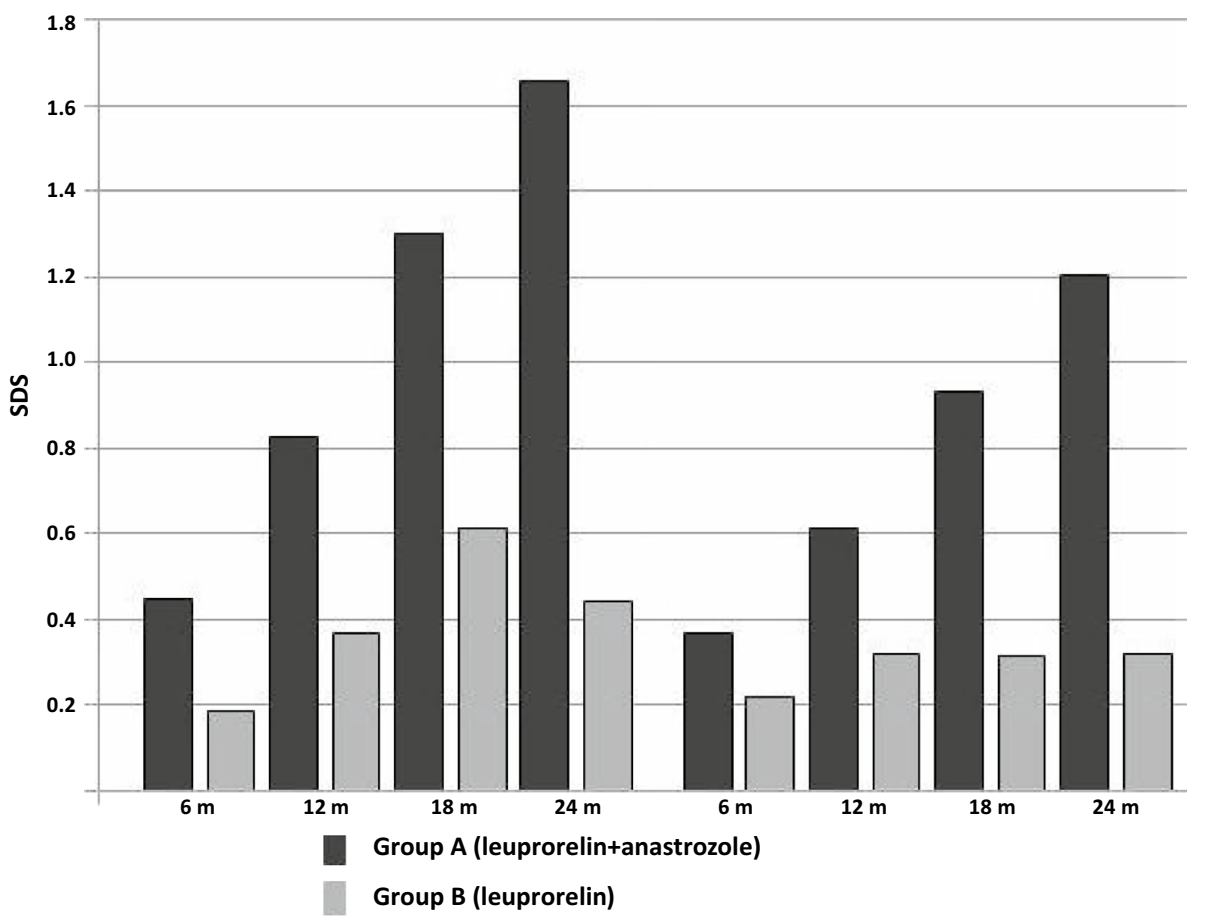

The theoretical concern of hyperandrogenism [16, 17] was overcome with the simultaneous use of LHRHa, keeping the gonadotropins and estradiol adequately suppressed. Thus, the small-even if not statistically significant-rise in testosterone levels could not result in any direct androgenic action on LH regulation [29]. Moreover, recent data on the use of AI as a treatment of infertility in the polycystic ovary syndrome are reasonably reassuring on safety concerns on possible direct deleterious effects on the ovaries [30, 31], whereas measurement of the anti-mullerian hormone levels may indeed be of value but only in the case of monotherapy with AI in girls [32].

The fact that gonadotropins and estradiol levels did not differ between the two groups implies that peripheral aromatization of mainly adrenal but also of ovarian androgens may be the main mechanism of BAA in these girls [1], with extragonadal estrogen biosynthesis, particularly in the bone, deploying a "paracrine" or "intracrine" action [33]. Moreover, the fact that estradiol levels, even if suppressed to below the detection limit in girls treated with leuprorelin for PP, do not correlate with the rate of skeletal maturation or linear growth [34] implies that AI may prove efficacious in delaying bone maturation even in prepubertal children with a compromised growth potential.

There was initially a significantly higher drop in HV in the anastrozole group that did initially raise concerns in some parents but without any implications on compliance. Although this finding did not persist, we speculate that it probably has to do with lower circulating levels of $E_{2}$ in group-A, even if still in the prepubertal range. This implies that we may use the least possible dose of an LHRHa if aromatase inhibitors are added. This approach would not only simplify follow-up but may prove cost-effective as well, as intensifying treatment with LHRHa is particularly costly.

Apart from the well-recognized and described pattern of Constitutional Advancement of Growth [35], that obviously does not require treatment, in girls with advanced puberty, borderline PP, precocious slowly progressive and early rapidly progressive puberty, inhibition of puberty alone does not result in significant improvement in terms of height at least after age 8 [19, 36, 37], and moreover its benefits in patients with atypical forms of early puberty not driven by LH (i.e. exaggerated adrenarche followed by early puberty) are not well defined [20]. The co-administration of AI appears to provide the potential for meaningful height gain in girls with borderline precocious or early—rapidly progressive or not—puberty, apart from the individualized possible psychological relief that pubertal inhibition might offer. One might also consider starting an LHRHa alone and add an AI in those cases that BAA does not respond to treatment [18]. It is noteworthy that the maximum gain in the girls treated with leuprorelin only in our study was observed at 18 months $(+3.16 \mathrm{~cm})$ and that further continuation of pubertal inhibition may indeed result in loss rather than in further gain as far as PAH is concerned, which is in accordance with Carel et al. [24]. This was not the case in group-A, who continued to ameliorate their PAH at 24 months. In any case the decision on the duration of the intervention must be individualized taking into account the patient's age, $\mathrm{HV}$, and response of BAA to the combined treatment. Aiming at the lowest normal female adult height or at an SDS lower than 
the patient's TH may be an acceptable target with a reasonable rationale from the doctor as well as the patient and their family.

The fact that bone mineral density, hematologic, biochemical, and lipid profiles did not show any changes during treatment suggests that the co-administration of AI with an LHRHa in girls is safe. Moreover, having excluded from the study children with possible bone diseases or abnormalities, the thorough examination of lumbar spine X-rays before and during treatment showed no alterations. This relieves the concern that was raised by Hero et al. [38], who reported the detection of asymptomatic or mildly symptomatic vertebral wedge deformities in boys with ISS previously treated with letrozole vs placebo, although there was no statistical difference between the occurrence rate in the two groups and baseline studies were not performed. In addition, very recently it was reported that more than $20 \%$ of children with ISS present skeletal dysplasia [39].

Further follow-up is needed to examine whether this gain in PAH is translated indeed in higher near-adult height in these girls after discontinuation of treatment.

In conclusion, inhibition of puberty with leuprorelin and co-administration of the third generation aromatase inhibitor anastrozole for up to 2 years is a safe and effective strategy in ameliorating poor PAH in girls with early puberty and a compromised growth potential. Further studies are needed to confirm these results, to evaluate the effect of $\mathrm{AI}$ on adult height, as well as long-term safety of the use of AI in girls.

\section{Compliance with ethical standards}

Conflict of interest The authors declare no conflict of interest relevant to this manuscript.

Ethical approval All procedures performed in studies involving human participants were in accordance with the ethical standards of the institutional and/or national research committee and with the 1964 Helsinki declaration and its later amendments or comparable ethical standards.

Informed consent Informed consent was obtained from all individual participants included in the study.

Open Access This article is distributed under the terms of the Creative Commons Attribution 4.0 International License (http://creativecommons.org/licenses/by/4.0/), which permits unrestricted use, distribution, and reproduction in any medium, provided you give appropriate credit to the original author(s) and the source, provide a link to the Creative Commons license, and indicate if changes were made.

\section{References}

1. Dunkel L (2006) Use of aromatase inhibitors to increase final height. Mol Cell Endocrinol 254-255:207-216. doi:10.1016/j. mce.2006.04.031
2. Dunkel L (2009) Update on the role of aromatase inhibitors in growth disorders. Horm Res 71(Suppl 1):57-63. doi:10.1159/000178040

3. Wickman S, Sipila I, Ankarberg-Lindgren C, Norjavaara E, Dunkel L (2001) A specific aromatase inhibitor and potential increase in adult height in boys with delayed puberty: a randomised controlled trial. Lancet 357(9270):1743-1748. doi:10.1016/ S0140-6736(00)04895-9

4. Hero M, Norjavaara E, Dunkel L (2005) Inhibition of estrogen biosynthesis with a potent aromatase inhibitor increases predicted adult height in boys with idiopathic short stature: a randomized controlled trial. J Clin Endocrinol Metab 90(12):63966402. doi:10.1210/jc.2005-1392

5. Neely EK, Kumar RB, Payne SL, Ranadive SA, Suchet DI (2014) Letrozole vs anastrozole for height augmentation in short pubertal males: first year data. J Clin Endocrinol Metab 99(11):4086-4093. doi:10.1210/jc.2014-2432

6. Rothenbuhler A, Linglart A, Bougneres P (2015) A randomized pilot trial of growth hormone with anastrozole versus growth hormone alone, starting at the very end of puberty in adolescents with idiopathic short stature. Int J Pediatr Endocrinol 1:4. doi:10.1186/1687-9856-2015-4

7. Mauras N, Welch S, Rini A, Klein KO (2004) An open label 12-month pilot trial on the effects of the aromatase inhibitor anastrozole in growth hormone $(\mathrm{GH})$-treated $\mathrm{GH}$ deficient adolescent boys. J Pediatr Endocrinol Metab JPEM 17(12):1597-1606

8. Eyssette-Guerreau S, Pinto G, Sultan A, Le Merrer M, Sultan C, Polak M (2008) Effectiveness of anastrozole and cyproterone acetate in two brothers with familial male precocious puberty. $\mathbf{J}$ Pediatr Endocrinol Metab JPEM 21(10):995-1002

9. Plourde PV, Reiter EO, Jou HC, Desrochers PE, Rubin SD, Bercu BB, Diamond FB Jr, Backeljauw PF (2004) Safety and efficacy of anastrozole for the treatment of pubertal gynecomastia: a randomized, double-blind, placebo-controlled trial. J Clin Endocrinol Metab 89(9):4428-4433. doi:10.1210/jc.2004-0082

10. Riepe FG, Baus I, Wiest S, Krone N, Sippell WG, Partsch CJ (2004) Treatment of pubertal gynecomastia with the specific aromatase inhibitor anastrozole. Horm Res 62(3):113-118. doi:10.1159/000079882

11. Shulman DI, Francis GL, Palmert MR, Eugster EA, Drug ftLWPES, Committee T, (2008) Use of aromatase inhibitors in children and adolescents with disorders of growth and adolescent development. Pediatrics 121(4):e975-e983. doi:10.1542/ peds.2007-2081

12. Mieszczak J, Lowe ES, Plourde P, Eugster EA (2008) The aromatase inhibitor anastrozole is ineffective in the treatment of precocious puberty in girls with McCune-Albright syndrome. J Clin Endocrinol Metab 93(7):2751-2754. doi:10.1210/jc.2007-2090

13. Albers N, Jorgens S, Deiss D, Hauffa BP (2002) McCuneAlbright syndrome- the German experience. J Pediatr Endocrinol Metab JPEM 15(Suppl 3):897-901

14. Alves C, Silva SF (2012) Partial benefit of anastrozole in the long-term treatment of precocious puberty in McCune-Albright syndrome. J Pediatr Endocrinol Metab JPEM 25(3-4):323-325

15. Engiz O, Berberoglu M, Siklar Z, Bilir P, Ocal G (2009) Treatment of autonomous ovarian follicular cyst with long-term anastrozole therapy. Indian J Pediatr 76(9):950-951. doi:10.1007/ s12098-009-0190-2

16. Mauras N (2009) Strategies for maximizing growth in puberty in children with short stature. Endocrinol Metab Clin North Am 38(3):613-624. doi:10.1016/j.ecl.2009.06.004

17. Geffner ME (2009) Aromatase inhibitors to augment height: continued caution and study required. J Clin Res Pediatr Endocrinol 1(6):256-261. doi:10.4274/jcrpe.v1i6.256 
18. Papadimitriou DT, Papadimitriou A (2010) An open label 1-3 year clinical trial on the effects of the aromatase inhibitor Anastrazole combined to the LHRH analogue Leuprorelin in girls with compromised growth potential. Paper presented at the Endocrine Society Meeting, San Diego

19. Bouvattier C, Coste J, Rodrigue D, Teinturier C, Carel JC, Chaussain JL, Bougneres PF (1999) Lack of effect of GnRH agonists on final height in girls with advanced puberty: a randomized long-term pilot study. J Clin Endocrinol Metab 84(10):3575-3578. doi:10.1210/jcem.84.10.6032

20. Willemsen RH, Elleri D, Williams RM, Ong KK, Dunger DB (2014) Pros and cons of GnRHa treatment for early puberty in girls. Nat Rev Endocrinol 10(6):352-363. doi:10.1038/ nrendo.2014.40

21. Papadimitriou A, Pantsiotou S, Douros K, Papadimitriou DT, Nicolaidou P, Fretzayas A (2008) Timing of pubertal onset in girls: evidence for non-Gaussian distribution. J Clin Endocrinol Metab 93(11):4422-4425. doi:10.1210/jc.2008-0661

22. Tarim O (2013) Height predictions by Bayley-Pinneau method may misguide pediatric endocrinologists. Turk $\mathrm{J}$ Pediatr 55(5):485-492

23. Kirkland JL, Gibbs AR, Kirkland RT, Clayton GW (1981) Height predictions in girls with idiopathic precocious puberty by the Bayley-Pinneau method. Pediatrics 68(2):251-252

24. Carel JC, Chaussain JL (1999) Gonadotropin releasing hormone agonist treatment for central precocious puberty. Horm Res Paediatr 51(Suppl 3):64-69

25. Papadimitriou A, Kanakis G, Douros K, Papadimitriou DT, Boutsiadis AH, Nicolaidou P, Fretzayas A (2011) Constitutional advancement of growth is associated with early puberty in girls. Horm Res Paediatr 76(4):273-277. doi:10.1159/000330005

26. Hadji P, Aapro MS, Body JJ, Bundred NJ, Brufsky A, Coleman RE, Gnant M, Guise T, Lipton A (2011) Management of aromatase inhibitor-associated bone loss in postmenopausal women with breast cancer: practical guidance for prevention and treatment. Ann Oncol 22(12):2546-2555. doi:10.1093/annonc/ mdr017

27. Carel J-C, Eugster EA, Rogol A, Ghizzoni L, Palmert MR, Group obotmotE-LGACC (2009) Consensus statement on the use of gonadotropin-releasing hormone analogs in children. Pediatrics 123(4):e752-e762. doi:10.1542/peds.2008-1783

28. Turpin ALPJ, Karmazin A, Moore WV, Jacobson JD (2004) Aromatase inhibitor may delay skeletal maturation and improve final adult height in females. Horm Res 62(suppl 2):140-198. doi: $10.1159 / 000081147$

29. Papadimitriou DT, Linglart A, Morel Y, Chaussain JL (2006) Puberty in subjects with complete androgen insensitivity syndrome. Horm Res 65(3):126-131. doi:10.1159/000091592
30. Legro RS, Brzyski RG, Diamond MP, Coutifaris C, Schlaff WD, Casson P, Christman GM, Huang H, Yan Q, Alvero R, Haisenleder DJ, Barnhart KT, Bates GW, Usadi R, Lucidi S, Baker V, Trussell JC, Krawetz SA, Snyder P, Ohl D, Santoro N, Eisenberg E, Zhang H, Network NRM (2014) Letrozole versus clomiphene for infertility in the polycystic ovary syndrome. N Engl J Med 371(2):119-129. doi:10.1056/NEJMoa1313517

31. Casper RF, Mitwally MF (2012) A historical perspective of aromatase inhibitors for ovulation induction. Fertil Steril 98(6):1352-1355. doi:10.1016/j.fertnstert.2012.10.008

32. Winkler N, Bukulmez O, Hardy DB, Carr BR (2010) Gonadotropin releasing hormone antagonists suppress aromatase and antiMullerian hormone expression in human granulosa cells. Fertil Steril 94(5):1832-1839. doi:10.1016/j.fertnstert.2009.09.032

33. Grumbach MM, Auchus RJ (1999) Estrogen: consequences and implications of human mutations in synthesis and action. J Clin Endocrinol Metab 84(12):4677-4694. doi:10.1210/ jcem.84.12.6290

34. Kunz GJ, Sherman TI, Klein KO (2007) Luteinizing hormone (LH) and estradiol suppression and growth in girls with central precocious puberty: is more suppression better? Are pre-injection LH levels useful in monitoring treatment? J Pediatr Endocrinol Metab JPEM 20(11):1189-1198

35. Papadimitriou A, Nicolaidou P, Fretzayas A, Chrousos GP (2010) Clinical review: Constitutional advancement of growth, a.k.a. early growth acceleration, predicts early puberty and childhood obesity. J Clin Endocrinol Metab 95(10):4535-4541. doi:10.1210/jc.2010-0895

36. Carel JC, Lahlou N, Roger M, Chaussain JL (2004) Precocious puberty and statural growth. Human Reprod Update 10(2):135147. doi:10.1093/humupd/dmh012

37. Lazar L, Kauli R, Pertzelan A, Phillip M (2002) Gonadotropinsuppressive therapy in girls with early and fast puberty affects the pace of puberty but not total pubertal growth or final height. J Clin Endocrinol Metab 87(5):2090-2094. doi:10.1210/ jcem.87.5.8481

38. Hero M, Makitie O, Kroger H, Nousiainen E, Toiviainen-Salo S, Dunkel L (2009) Impact of aromatase inhibitor therapy on bone turnover, cortical bone growth and vertebral morphology in preand peripubertal boys with idiopathic short stature. Horm Res 71(5):290-297. doi:10.1159/000208803

39. Flechtner I, Lambot-Juhan K, Teissier R, Colmenares A, Baujat G, Beltrand J, Ajaltouni Z, Pauwels C, Pinto G, Samara-Boustani D, Simon A, Thalassinos C, Le Merrer M, Cormier-Daire V, Polak M (2014) Unexpected high frequency of skeletal dysplasia in idiopathic short stature and small for gestational age patients. Eur J Endocrinol/Eur Fed Endocr Soc 170(5):677-684. doi:10.1530/EJE-13-0864 